\title{
SUPPORTING INFORMATON
}

\section{Conductance of Curved 3M-1 Armchair Graphene Nanoribbons}

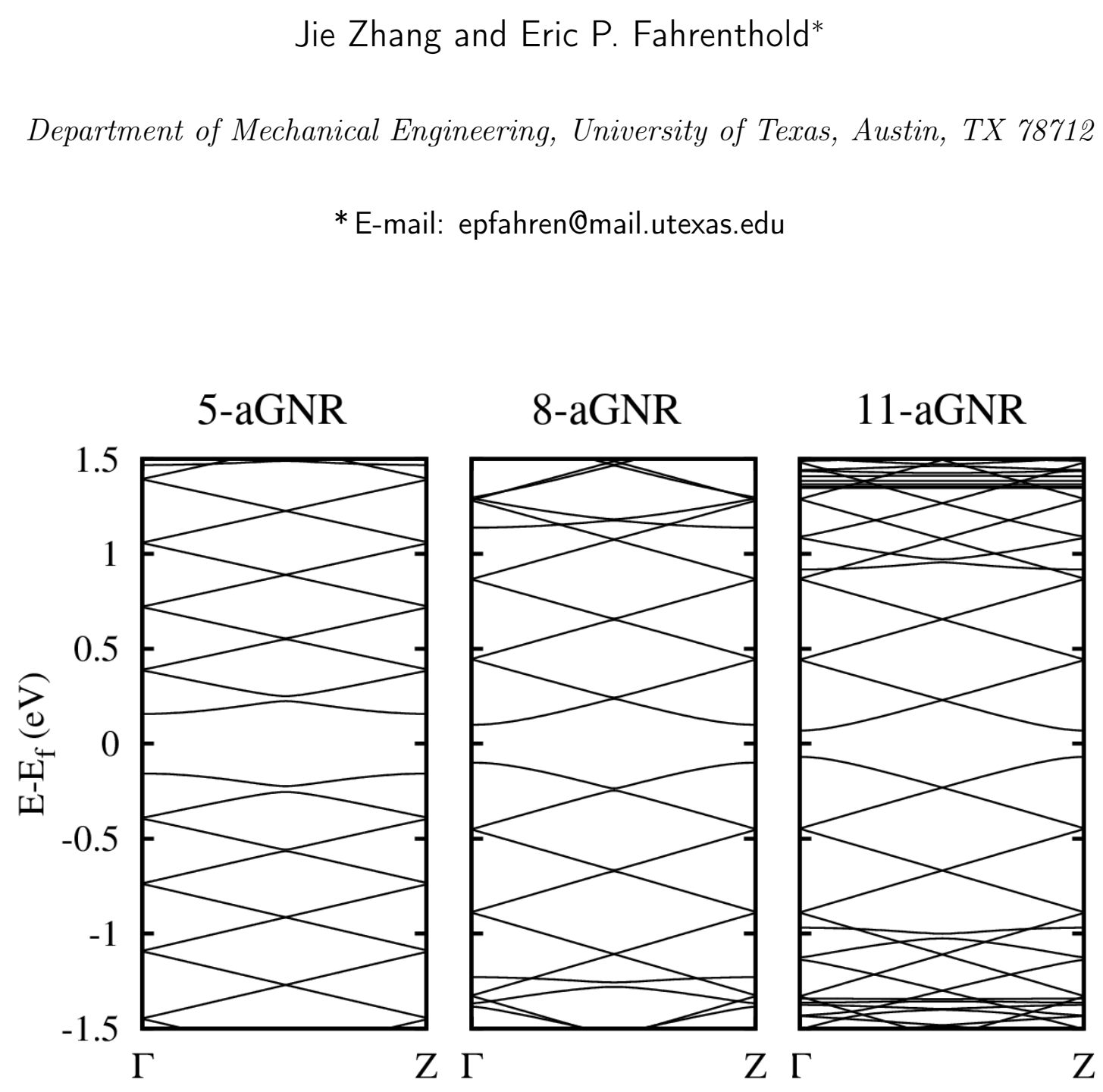

Figure S1: Band diagrams for flat aGNRs at zero bias (left, 5-aGNR; middle, 8-aGNR; right, 11-aGNR). 


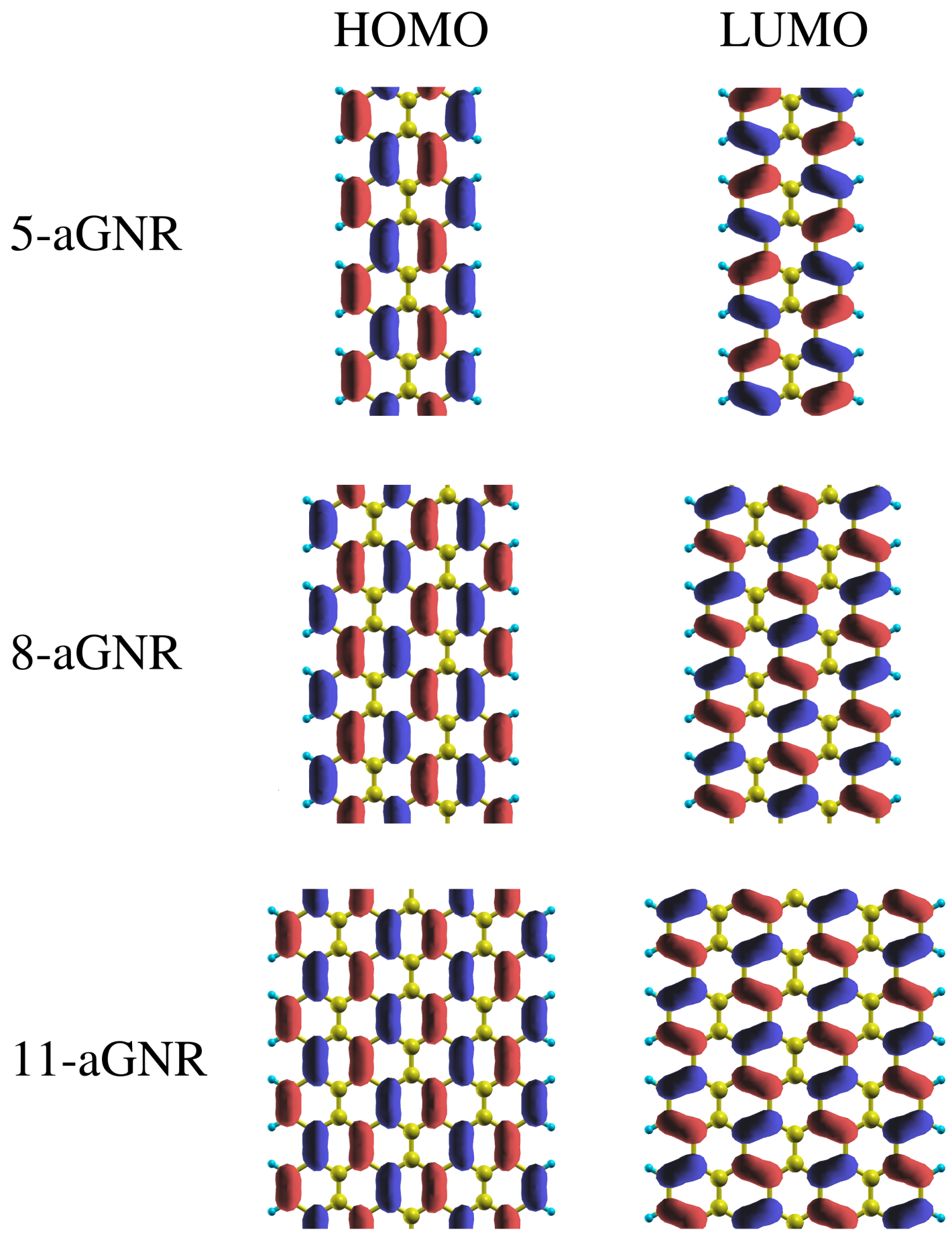

Figure S2: HOMO-LUMO orbitals for flat aGNRs at zero bias (left, HOMO; right, LUMO; top, 5-aGNR; middle, 8-aGNR; bottom, 11-aGNR). 
Table S1: Computed currents (amps) for curved 5-aGNRs at a length of 10 unit cells.

\begin{tabular}{|c|c|c|c|c|}
\hline \multirow{2}{*}{$\begin{array}{c}\text { Radius of curvature } \\
\text { (angstroms) }\end{array}$} & \multicolumn{4}{|c|}{ Bias voltage (volts) } \\
\cline { 2 - 5 } & 0.2 & 0.4 & 0.6 & 0.8 \\
\hline$\infty$ & $5.23 \mathrm{E}-10$ & $6.75 \mathrm{E}-07$ & $3.01 \mathrm{E}-06$ & $6.64 \mathrm{E}-06$ \\
\hline 100 & $5.28 \mathrm{E}-10$ & $7.02 \mathrm{E}-07$ & $3.08 \mathrm{E}-06$ & $6.74 \mathrm{E}-06$ \\
\hline 50 & $6.08 \mathrm{E}-10$ & $7.41 \mathrm{E}-07$ & $3.29 \mathrm{E}-06$ & $7.22 \mathrm{E}-06$ \\
\hline 30 & $5.36 \mathrm{E}-10$ & $6.84 \mathrm{E}-07$ & $3.05 \mathrm{E}-06$ & $6.69 \mathrm{E}-06$ \\
\hline 20 & $4.58 \mathrm{E}-10$ & $6.06 \mathrm{E}-07$ & $2.72 \mathrm{E}-06$ & $6.00 \mathrm{E}-06$ \\
\hline 15 & $3.70 \mathrm{E}-10$ & $5.09 \mathrm{E}-07$ & $2.30 \mathrm{E}-06$ & $5.13 \mathrm{E}-06$ \\
\hline 14 & $3.48 \mathrm{E}-10$ & $4.80 \mathrm{E}-07$ & $2.17 \mathrm{E}-06$ & $4.88 \mathrm{E}-06$ \\
\hline 13 & $3.25 \mathrm{E}-10$ & $4.52 \mathrm{E}-07$ & $2.05 \mathrm{E}-06$ & $4.62 \mathrm{E}-06$ \\
\hline 12 & $2.97 \mathrm{E}-10$ & $4.19 \mathrm{E}-07$ & $1.90 \mathrm{E}-06$ & $4.29 \mathrm{E}-06$ \\
\hline 10 & $2.78 \mathrm{E}-10$ & $3.77 \mathrm{E}-07$ & $1.71 \mathrm{E}-06$ & $3.89 \mathrm{E}-06$ \\
\hline 8.5 & $2.50 \mathrm{E}-10$ & $3.40 \mathrm{E}-07$ & $1.55 \mathrm{E}-06$ & $3.55 \mathrm{E}-06$ \\
\hline 8 & $1.86 \mathrm{E}-10$ & $2.62 \mathrm{E}-07$ & $1.20 \mathrm{E}-06$ & $2.73 \mathrm{E}-06$ \\
\hline 7.5 & $1.28 \mathrm{E}-10$ & $1.81 \mathrm{E}-07$ & $8.58 \mathrm{E}-07$ & $2.08 \mathrm{E}-06$ \\
\hline 6.8 & $6.34 \mathrm{E}-11$ & $9.30 \mathrm{E}-08$ & $4.71 \mathrm{E}-07$ & $1.25 \mathrm{E}-06$ \\
\hline
\end{tabular}

Table S2: Computed currents (amps) for curved 8-aGNRs at a length of 6 unit cells.

\begin{tabular}{|c|c|c|c|c|}
\hline \multirow{2}{*}{$\begin{array}{c}\text { Radius of curvature } \\
\text { (angstroms) }\end{array}$} & \multicolumn{4}{|c|}{ Bias voltage (volts) } \\
\cline { 2 - 5 } & 0.2 & 0.4 & 0.6 & 0.8 \\
\hline$\infty$ & $1.89 \mathrm{E}-07$ & $6.37 \mathrm{E}-06$ & $1.47 \mathrm{E}-05$ & $2.63 \mathrm{E}-05$ \\
\hline 50 & $1.98 \mathrm{E}-07$ & $6.61 \mathrm{E}-06$ & $1.52 \mathrm{E}-05$ & $2.72 \mathrm{E}-05$ \\
\hline 30 & $1.95 \mathrm{E}-07$ & $6.49 \mathrm{E}-06$ & $1.50 \mathrm{E}-05$ & $2.67 \mathrm{E}-05$ \\
\hline 10 & $1.59 \mathrm{E}-07$ & $5.15 \mathrm{E}-06$ & $1.18 \mathrm{E}-05$ & $2.12 \mathrm{E}-05$ \\
\hline 7 & $1.29 \mathrm{E}-07$ & $4.14 \mathrm{E}-06$ & $9.49 \mathrm{E}-06$ & $1.72 \mathrm{E}-05$ \\
\hline 6 & $9.81 \mathrm{E}-08$ & $3.15 \mathrm{E}-06$ & $7.22 \mathrm{E}-06$ & $1.30 \mathrm{E}-05$ \\
\hline 5 & $7.39 \mathrm{E}-08$ & $2.38 \mathrm{E}-06$ & $5.48 \mathrm{E}-06$ & $9.99 \mathrm{E}-06$ \\
\hline
\end{tabular}


Table S3: Computed currents (amps) for curved 11-aGNRs at a length of 6 unit cells.

\begin{tabular}{|c|c|c|c|c|}
\hline \multirow{2}{*}{$\begin{array}{c}\text { Radius of curvature } \\
\text { (angstroms) }\end{array}$} & \multicolumn{4}{|c|}{ Bias voltage (volts) } \\
\cline { 2 - 5 } & 0.2 & 0.4 & 0.6 & 0.8 \\
\hline$\infty$ & $9.86 \mathrm{E}-07$ & $1.21 \mathrm{E}-05$ & $2.40 \mathrm{E}-05$ & $3.71 \mathrm{E}-05$ \\
\hline 500 & $9.88 \mathrm{E}-07$ & $1.21 \mathrm{E}-05$ & $2.40 \mathrm{E}-05$ & $3.72 \mathrm{E}-05$ \\
\hline 200 & $9.94 \mathrm{E}-07$ & $1.22 \mathrm{E}-05$ & $2.42 \mathrm{E}-05$ & $3.74 \mathrm{E}-05$ \\
\hline 100 & $1.02 \mathrm{E}-06$ & $1.25 \mathrm{E}-05$ & $2.47 \mathrm{E}-05$ & $3.81 \mathrm{E}-05$ \\
\hline 50 & $1.01 \mathrm{E}-06$ & $1.23 \mathrm{E}-05$ & $2.43 \mathrm{E}-05$ & $3.81 \mathrm{E}-05$ \\
\hline 30 & $9.79 \mathrm{E}-07$ & $1.19 \mathrm{E}-05$ & $2.35 \mathrm{E}-05$ & $3.65 \mathrm{E}-05$ \\
\hline 20 & $9.31 \mathrm{E}-07$ & $1.12 \mathrm{E}-05$ & $2.22 \mathrm{E}-05$ & $3.46 \mathrm{E}-05$ \\
\hline 15 & $8.91 \mathrm{E}-07$ & $1.06 \mathrm{E}-05$ & $2.11 \mathrm{E}-05$ & $3.30 \mathrm{E}-05$ \\
\hline 12 & $8.55 \mathrm{E}-07$ & $1.02 \mathrm{E}-05$ & $2.01 \mathrm{E}-05$ & $3.17 \mathrm{E}-05$ \\
\hline 9 & $7.96 \mathrm{E}-07$ & $9.37 \mathrm{E}-06$ & $1.86 \mathrm{E}-05$ & $2.94 \mathrm{E}-05$ \\
\hline 6 & $6.01 \mathrm{E}-07$ & $6.95 \mathrm{E}-06$ & $1.39 \mathrm{E}-05$ & $2.16 \mathrm{E}-05$ \\
\hline 5 & $4.54 \mathrm{E}-07$ & $5.23 \mathrm{E}-06$ & $1.05 \mathrm{E}-05$ & $1.64 \mathrm{E}-05$ \\
\hline
\end{tabular}

